\title{
Halophytes-associated endophytic and rhizospheric bacteria: diversity, antagonism and metabolite production
}

\author{
Authors: Fehmida Bibi, Gary A. Strobel, Muhammad \\ Yasir, Ahmed Abdullah Khalaf, and Esam Ibrahim \\ Azhar
}

This is an Accepted Manuscript of an article published in Biocontrol Science and Technology on February 15, 2018, available online: http://www.tandfonline.com/10.1080/09583157.2018.1434868.

Bibi, Fehmida, Gary Allan Strobel, Muhammad Imran Naseer, Muhammad Yasir, Ahmed Abdullah Khalaf Al-Ghamdi, and Esam Ibrahim Azhar. "Halophytes-associated endophytic and rhizospheric bacteria: diversity, antagonism and metabolite production." Biocontrol Science and Technology 28, no. 2 (February 2018): 192-213. DOI: 10.1080/09583157.2018.1434868.

Made available through Montana State University's $\underline{\text { ScholarWorks }}$ scholarworks. montana.edu 


\title{
Halophytes-associated endophytic and rhizospheric bacteria: diversity, antagonism and metabolite production
}

\author{
Fehmida Bibi (D) ${ }^{a}$, Gary Allan Strobel ${ }^{b}$, Muhammad Imran Naseer ${ }^{c}$, Muhammad Yasir ${ }^{a}$, \\ Ahmed Abdullah Khalaf Al-Ghamdi ${ }^{d}$ and Esam Ibrahim Azhar ${ }^{\text {a,d }}$ \\ ${ }^{a}$ Special Infectious Agents Unit, King Fahd Medical Research Center, King Abdulaziz University, Jeddah, Saudi \\ Arabia; 'bepartment of Plant Sciences, Montana State University, Bozeman, MT, USA; 'Center of Excellence in \\ Genomic Medicine Research (CEGMR), King Abdulaziz University, Jeddah, Saudi Arabia; ${ }^{d}$ Department of \\ Medical Laboratory Technology, Faculty of Applied Medical Sciences, King Abdulaziz University, Jeddah, \\ Saudi Arabia
}

\begin{abstract}
In Saudi Arabia, halophytes occupy tidal and intertidal forest ecosystems. They and their associated microflora have immense potential to yield novel and important useful natural products. Three halophytes (Avicennia marina, Halocnemum strobilaceum, Zygophyllum qatarense) were targeted for the isolation and identification of populations of endophytic and rhizospheric bacteria having antimicrobial potential. A total 554 bacterial isolates were initially screened against oomycetes fungal pathogens, Phytophthora capsici and Pythium ultimum. Of these, only 57 rhizospheric and endophytic bacteria exhibited inhibition against the targeted bioassay oomycetes. Tentative identification of the bacteria was on the basis of 16S rRNA gene sequences which revealed $92-100 \%$ sequence identity to type strains of related species and placed these organisms in six major classes: Actinobacteria, $\gamma$-Proteobacteria, Firmicutes, a-Proteobacteria, Flavobacteriia and $\beta$-Proteobacteria. When checked for lytic enzyme production, mostly the isolates of Actinobacteria and Firmicutes were potential enzyme producers. Detection of secondary metabolite biosynthetic genes - type I polyketide synthases, type II polyketide synthases and nonribosomal peptide synthetases - confirmed that $21(35.5 \%)$ isolates were positive for at least one type of the biosynthetic gene. In order to identify metabolites, three isolates, Alteromonas australica (EA73), Aidingimonas halophila (EA105) and Halomonas zincidurans (EA127), were selected and subjected to chemical analyses using liquid chromatography-mass spectrometry and gas chromatography-mass spectrometry. Both analyses showed the presence of different bioactive compounds in the culture extracts of isolates some of which are already reported for their diverse biological activities such as 2, 4-Diacetylphloroglucinol. Our results demonstrated that halophytes represent an important source of potentially active bacteria producing antifungal metabolites of medical significance.
\end{abstract}




\section{Introduction}

Halophytes inhabit the intertidal areas of Saudi Arabia and they consist of populations of grasses, epiphytes, shrubs and trees. Among halophytes, mangroves exist in tropical climates requiring warm conditions and can tolerate salinity, anaerobic conditions, tides, winds and high temperatures. Their habitat enables them to grow with rich biodiversity. Mangroves under these stressful conditions are able to produce different kinds of active metabolites with diverse biological functions. Until now, more than 200 active metabolites have been isolated from mangroves (Bandaranayake, 2002).

Mangroves are a good source of steroids, saponins, flavonoids, triterpenes, alkaloids, tannins and have been used in different traditional medicines due to the antimicrobial activities of their extracts (Eldeen \& Effendy, 2013). Previous studies reported a wide range of biological activities such as antiviral, antibacterial and antifungal properties of plant extracts (Chandrasekaran, Kannathasan, Venkatesalu, \& Prabhakar, 2009; Premanathan et al., 2009). Due to their biological activities, they are an ideal material for investigation of associated microorganisms and their bioactive compounds. Both rhizospheric and endophytic bacteria seem to play important roles for the survival and growth of host plants. They provide several beneficial effects including plant growth promotion and resistance against pathogens by producing different substances such as volatile and antifungal compounds (Chung et al., 2008; Ryu et al., 2003). Halophytes also harbour different groups of bacteria, and these bacteria perform different functions such as growth promotion and disease resistance against different pathogens (Thatoi, Behera, Mishra, \& Dutta, 2013). Bacterial communities associated with halophytes are beneficial for the host whether as rhizospheric bacteria (Roy, Hens, Biswas, Biswas, \& Kumar, 2002) or in endophytic form (Garcias-Bonet, Arrieta, de Santana, Duarte, \& Marbà, 2012; Hu, $\mathrm{Li}, \& \mathrm{He}, 2010$ ). These bacteria are also an excellent source of different useful enzymes and antibiotics (Thatoi et al., 2013).

Many halophytes have associated endophytic bacteria that possess a broad spectrum of antifungal activities against different pathogenic bacteria (Hu et al., 2010; Jose \& Christy, 2013). Recently, new marine compounds such as isocoumarin, furanocoumarin and kandenol have been reported from halophyte-associated bacteria (Xu, 2015); however, there are limited studies on isolation of bacteria from halophytes in coastal areas of the Red Sea and their associated identification and biological activities. In a recent study from Saudi Arabia, microbial communities from a mangrove (Avicennia marina) were identified using a metagenomic approach but no functional aspects of the microbes involved have been studied (Alzubaidy et al., 2016). Therefore, we designed a study to isolate both rhizospheric and endophytic bacteria from different parts of halophytes, $A$. marina, Halocnemum strobilaceum and Zygophyllum qatarense, and to perform a tentative identification of the strains using $16 \mathrm{~S}$ rDNA molecular techniques and screened them against different phytopathogens. We also report enzyme production, secondary metabolite biosynthetic genes and the identification of metabolites from selected bacterial isolates. Three potential bacteria were selected for identification of metabolites and antimicrobial compounds such as 2,4-Diacetylphloroglucinol (DAPG), prednicarbate, benzydamine, methyl jasmonate, cephaloridine and triamcinolone acetonide were discovered. 


\section{Materials and methods}

\section{Sample collection and isolation of rhizospheric bacteria from halophytes}

Three different halophytes specimens [A. marina (mangrove), H. strobilaceum and Z. qatarense)] were collected from the coastal area of Thuwal, Jeddah, Saudi Arabia $\left(22^{\circ}\right.$ $15^{\prime} 54^{\prime \prime}$ North, $39^{\circ} 6^{\prime} 44^{\prime \prime}$ East). All of the plant specimens were placed in a sterile bag after collection and transferred to the laboratory for bacterial isolation. Soil, roots, leaves and pneumatophores of halophytes were used for the isolation of rhizospheric and endophytic bacteria. To isolate bacteria from soil adhering to roots of the plants, they were dipped in sterile distilled water and serial dilutions were made $\left(10^{-3}, 10^{-4}\right.$ and $\left.10^{-5}\right)$ in filtered autoclaved seawater (FAS) and spread in triplicates on four different media used for culturing of bacteria. Half strength R2A ( $1 \frac{12}{2}$ R2A) [0.25 g yeast extract; $0.25 \mathrm{~g}$ Proteose Peptone No. 3 (Difco Laboratories, Detroit, MI); $0.25 \mathrm{~g}$ casamino acid; $0.25 \mathrm{~g}$ dextrose; $0.25 \mathrm{~g}$ soluble starch; $0.15 \mathrm{~g}$ sodium pyruvate; $0.15 \mathrm{~g} \mathrm{~K}_{2} \mathrm{HPO}_{4} ; 0.03 \mathrm{~g} \mathrm{MgSO}_{4}$ ], half strength Tryptic soy agar (1/2 TSA) [pancreatic digest of casein $7.5 \mathrm{~g}$; papain digest of soybean $2.5 \mathrm{~g}$; $\mathrm{NaCl} 2.5 \mathrm{~g}$; agar $15.0 \mathrm{~g}$ ], marine agar (MA) [peptone $5.0 \mathrm{~g}$; yeast extract $1.0 \mathrm{~g}$; Ferric Citrate $0.1 \mathrm{~g}$; $\mathrm{NaCl}$ $19.45 \mathrm{~g} ; \mathrm{MgCl} 8.8 \mathrm{~g} ; \mathrm{Na}_{2} \mathrm{SO}_{4} 3.24 \mathrm{~g} ; \mathrm{CaCl} 1.8 \mathrm{~g} ; \mathrm{KCl} 0.55 \mathrm{~g} ; \mathrm{NaHCO}_{3} 0.16 \mathrm{~g} ; \mathrm{KBr}$; $0.08 \mathrm{~g} ; \mathrm{SrCl}_{2} 34.0 \mathrm{mg} ; \mathrm{H}_{3} \mathrm{BO}_{3} 22.0 \mathrm{mg} ; \mathrm{Na}_{2} \mathrm{SiO}_{3} 4.0 \mathrm{mg} ; \mathrm{NaF} 2.4 \mathrm{mg} ; \mathrm{NH}_{4} \mathrm{NO}_{3}$ $1.6 \mathrm{mg} ; \mathrm{Na}_{2} \mathrm{HPO}_{4} 8.0 \mathrm{mg}$; agar $15.0 \mathrm{~g}$ ] and half nutrient agar $(1 / 2 \mathrm{NA})$ [beef extract $1.5 \mathrm{~g}$; peptone $2.5 \mathrm{~g}$; agar $15.0 \mathrm{~g}$ ] (Difco Laboratories) for bacterial culturing in $1000 \mathrm{~mL}$ filtered seawater for bacterial culturing. Roots and leaves tissues were also used for isolation of bacteria.

\section{Isolation of endophytic bacteria from halophytes}

For isolation of endophytic bacteria from plant roots, leaves and pneumatophores surface sterilisation was performed. Roots, leaves and pneumatophores segments were washed 5-6 times with tap water and then further sterilised by washing with disinfectants as described previously (Bibi, Yasir, Song, Lee, \& Chung, 2012). After sterilisation of roots, leaves and pneumatophores segments, small pieces of sterilised roots, leaves and pneumatophores segments were ground in FAS using sterile mortar and pestle. Aliquots were further serially diluted $\left(10^{-3}, 10^{-4}\right.$ and $\left.10^{-5}\right)$ and plated in triplicate on the four different media mentioned above. To suppress fungal growth, $50 \mu \mathrm{g} / \mathrm{mL}$ cycloheximide was mixed to the medium before pouring. Plates were incubated at $25^{\circ} \mathrm{C}$ for 2 weeks for bacterial growth. Individual colonies were further streaked to check the purity of the strains, and all these bacterial strains were further subcultured and stored in $15 \%$ (v/v) glycerol stock of strains at $-70^{\circ} \mathrm{C}$ in King Fahd Medical Research Centre and were given lab numbers from EA73-EA131, respectively.

\section{Screening of bacteria for antifungal activity}

Rhizospheric and endophytic bacteria isolated from halophytes were further screened for their antifungal potential. Five different fungal pathogens: Phytophthora capsici (P. capsici), Pythium ultimum (Py. ultimum), Magnaporthe grisea (obtained in this laboratory), Altenaria mali (KCTC 6972) and Fusarium moniliforme (KCTC 6149), were 
obtained from the Korean type culture collection centre (KCTC). Antagonistic activity against fungal pathogens was determined by using the cross streak method (Bibi et al., 2012). All isolates were streaked on PDA media supplemented with $1 / 2 \mathrm{R} 2 \mathrm{~A}$ in seawater. Each 6-mm mycelial disc of test fungal pathogens was placed in the centre of the plate perpendicular to the streak of isolates at $4 \mathrm{~cm}$ from the edges of the plate and was incubated for 4-6 days at $28^{\circ} \mathrm{C}$. All strains were checked twice for antagonistic activity. The antagonistic activity was then evaluated by measuring the inhibition zone of fungal mycelia around the bacterial colony.

\section{Extraction of bacterial DNA and 16S rRNA gene sequencing}

Genomic DNA was extracted from antagonistic bacteria using a DNA extraction kit (Thermo Scientific, Waltham, MA, USA). To identify antagonistic bacteria, 16S rRNA gene sequencing was performed. Using bacterial universal primers 27F ( $5^{\prime}$-AGAGTTTGATCCTGGCTCAG-3') and 1492R ( $5^{\prime}$-GGTTACCTTGTTACGACTT $-3^{\prime}$ ), the 16S rRNA gene fragment was amplified. Amplifications were performed under following conditions: one cycle of $95^{\circ} \mathrm{C}$ for $5 \mathrm{~min}$ followed by 28 cycles of $95^{\circ} \mathrm{C}$ for $1 \mathrm{~min}$, an annealing of $58^{\circ} \mathrm{C}$ for $50 \mathrm{~s}$ and extension at $72^{\circ} \mathrm{C}$ for $1 \mathrm{~min}$, with a final extension step at $72^{\circ} \mathrm{C}$ for $10 \mathrm{~min}$. Using PCR purification kit (Thermo Scientific), the PCR products were purified and sequenced commercially by Macrogen (Seoul, Korea). Sequences obtained after 16S rRNA gene similarity were identified using the EzTaxon server (http://eztaxon-e. ezbiocloud.net/) (Kim et al., 2012) to identify the bacteria. To determine the phylogenetic position of the antagonistic bacteria and related type strains, the 16S rRNA gene sequences of type strains were obtained from the National Center for Biotechnology Information. For the phylogenetic analysis, CLUSTALX (Thompson, Gibson, Plewniak, Jeanmougin, \& Higgins, 1997) multiple alignments of the bacterial sequences were performed and BioEdit software (Hall, 1999) was used to edit the gaps. The neighbour-joining method in the MEGA6 Programme with bootstrap values based on 1000 replications was used for constructing the phylogenetic tree (Tamura, Stecher, Peterson, Filipski, \& Kumar, 2013).

\section{Evaluation of hydrolytic enzymatic activity}

Protease activity was checked using skim milk $1 \frac{1}{2}$ R $2 \mathrm{~A}$ agar plates. Bacteria producing protease made clear zone on skim milk agar plates. Amylase production was checked on starch media. Amylase producing bacteria showed starch hydrolysis as a clear zone on starch 1/2 R2A agar plates (Kumar, Karan, Kapoor, Singh, \& Khare, 2012). For lipase activity, tributyrin $1 / 2 \mathrm{R} 2 \mathrm{~A}$ agar media was used. After $48 \mathrm{~h}$ of incubation at $28^{\circ} \mathrm{C}$, a clear zone was detected around bacteria that were hydrolysing tributyrin. To check cellulase activity, CMC agar (carboxymethylcellulose agar) media was used. Bacteria were streaked on plates of the respective enzyme media and incubated at $28^{\circ} \mathrm{C}$ for 2 days. After these plates were flooded with a solution of $0.1 \%$ Congo red and put on an orbital shaker for $15 \mathrm{~min}$ and washed with $1 \mathrm{M} \mathrm{NaCl}$ (Hendricks, Doyle, \& Hugley, 1995). Positive activity was seen as a halo zone around bacterial colonies on CMC agar. 


\section{Detection of secondary metabolite biosynthetic genes}

The detection of a biosynthetic gene, polyketide synthetase I (PKS-I) and nonribosomal peptide synthetase (NRPS) genes were checked using primer pairs K1F/M6R (5'TSAAGTCSAACATCGGBCA-3'; 5'-CGCAGGTTSCSGTACCAGTA-3') and A3F/A7R (5' GCSTACSYSATSTACACSTCSGG-3'; 5'-SASGTCVCCSGTSCGGTAS-3'), respectively (Ayuso-Sacido \& Genilloud, 2005). The polyketide synthetase II (PKS-II) gene was amplified using primer pair KSa/K $\beta$ (5'-TSGCSTGCTTGGAYGCSATC-3'; 5'TGGAANCCGCCGAABCCTCT-3') (Metsä-Ketelä et al., 1999). PCR amplification products were then checked by using $0.8 \%$ agarose gel electrophoresis, and bands of $1.2-$ $1.4 \mathrm{~kb}, 600 \mathrm{bp}$ and $700-800 \mathrm{bp}$ were detected as products of PKS-I, PKS-II and NRPS genes, respectively.

\section{Optimisation of bacterial culture condition for production of antifungal activity}

To optimise culture conditions of the selected bacterial strains for the production of antifungal activities, an appropriate medium for culturing was selected. Four different media, i.e. $1 / 2$ R2A broth, $1 / 2$ TSA, $1 / 2$ NA in seawater and Marine broth in distilled, were used for culturing. After every $24 \mathrm{~h}$, optical density (OD) was checked and antifungal activity was assessed against $P$. capsici and $P y$. ultimum using disc diffusion method. The effect of temperature was checked at different ranges of temperatures $\left(20-40^{\circ} \mathrm{C}\right)$ in $1 / 2 \mathrm{R} 2 \mathrm{~A}$ broth. For $\mathrm{pH}$ optimisation, different $\mathrm{pH}$ value ranges (5-12) were used for the growth and antifungal compound production in $1 / 2 \mathrm{R} 2 \mathrm{~A}$ broth.

\section{Gas chromatography-mass spectrometry analysis for identification of metabolites}

All chemicals and solvents were of MS grade. $\mathrm{N}, \mathrm{O}$-bis(trimethylsily) trifluoractamide + trimethylchlorosilane (TMCS) (99:1), Methoxyamine hydrochloride and Pyridine (R.G., Reag. ACS, Reag. Ph Eur) were purchased from Sigma-Aldrich, and methanol was purchased from Thermo Fisher. Bacterial cultures $(1 \mathrm{~mL})$ were lysed and centrifuged at $10,000 \mathrm{~g}$ for $10 \mathrm{~min}$. The supernatant $(200 \mu \mathrm{L})$ was transferred to a $1.5-\mathrm{mL}$ Eppendorf tube and $600 \mu \mathrm{L}$ acetonitrile was added and vortex for $30 \mathrm{~s}$. Samples were further centrifuge at $13,000 \mathrm{~g}$ for $10 \mathrm{~min}$ and $200 \mu \mathrm{L}$ supernatant was transferred to glass vials. The solvent was removed by a nitrogen dry machine. Further $80 \mu \mathrm{L}$ methoxy amine pyridine hydrochloride $(15 \mathrm{mg} / \mathrm{mL})$ was added to the glass-derived bottle, vortexed for $2 \mathrm{~min}$ and incubated at $80^{\circ} \mathrm{C}$ for $30 \mathrm{~min}$; $\mathrm{N}, \mathrm{O}$-bis(trimethylsily) trifluoractamide (BSTFA) $80 \mu \mathrm{L}$ containing $1 \%(\mathrm{v} / \mathrm{v})$ TMCS was added to each vial and the mixture was vortexed for $2 \mathrm{~min}$ and then derivatised at $80^{\circ} \mathrm{C}$ for $30 \mathrm{~min}$. Mixtures were centrifuged for $10 \mathrm{~min}(13,000 \mathrm{~g})$, then $100 \mu \mathrm{L}$ supernatant was used for gas chromatography-mass spectrometry (GC-MS) metabolomics analysis. The derivatised samples were analysed on Shimadzu GCMS-QP2010 Ultra, including a capillary column $(30 \mathrm{~m} \times 0.25 \mathrm{~mm} \times 0.25 \mu \mathrm{m})$ used to separate the derivatives. Helium (>99.999\%) was used as the carrier gas at a constant flow rate of $1 \mathrm{~mL} / \mathrm{min}$ through the column. The injector temperature was maintained at $260^{\circ} \mathrm{C}$ and injection volume was $1 \mu \mathrm{L}$ in spoutless mode. The initial oven temperature was $80^{\circ} \mathrm{C}$ and was held for $2 \mathrm{~min}$, ramped to $300^{\circ} \mathrm{C}$ at a rate of $10^{\circ} \mathrm{C} / \mathrm{min}$, and finally held at 
$300^{\circ} \mathrm{C}$ for $5 \mathrm{~min}$. The temperature of ion source (electron impact) was set to $200^{\circ} \mathrm{C}$. The collision energy was $70 \mathrm{eV}$. Mass data were acquired in a full-scan mode $(\mathrm{m} / \mathrm{z} 45-800)$, with an acquisition rate of 100 spectrum/s.

\section{Liquid chromatography-mass spectrometry analysis of bacterial culture}

Five millilitres of bacterial culture was placed on $-80^{\circ} \mathrm{C}$ for $5 \mathrm{~min}$ and then transferred to a $37^{\circ} \mathrm{C}$ water bath for $5 \mathrm{~min}$, and this procedure was repeated for five times. Centrifugation was done at $15,000 \mathrm{~g}$ for $10 \mathrm{~min}, 3 \mathrm{~mL}$ supernatant was transferred to a tube and $12 \mathrm{~mL}$ acetonitrile was added and vortexed for $30 \mathrm{~s}$. Again, centrifugation was done at $15000 \mathrm{~g}$ for $10 \mathrm{~min}$ and $300 \mu \mathrm{L}$ supernatant was taken for liquid chromatography-mass spectrometry (LC-MS) metabolomics analysis. Injection volume was $3 \mu \mathrm{L}$ and the samples are analysed on Agilent 6540B TOF/Q-TOF Mass Spectrometer coupled with Agilent 1290 UPLC and Dual AJS ESI ion source. An ACQUITY UPLC HSS T3 $(100 \times 2.1 \mathrm{~mm}$, $1.8 \mu \mathrm{m}$ ) column and pre-column (Phenomenex Security Guard ${ }^{\mathrm{TM}}$ ) was used to separate sample. The column temperature was set to $45^{\circ} \mathrm{C}$ and the flow rate was $0.5 \mathrm{~mL} / \mathrm{min}$. Acquisition range was from 50 to $1500 \mathrm{~m} / z$, and scan rate was $1.00 \mathrm{spectrum} / \mathrm{s}$. MS parameters were set as follows: capillary voltage $3500 \mathrm{~V}$, nebulizer pressure 35 psi, drying gas $10 \mathrm{~L} / \mathrm{min}$, gas temperature $325^{\circ} \mathrm{C}$, vaporizer $200 \mathrm{~V}$, voltage charge $1000 \mathrm{~V}$; negative-ion mode capillary voltage $3500 \mathrm{~V}$, corona negative $15.0 \mathrm{~V}$, fragmentor $175 \mathrm{~V}$, skimmer 1 $65.0 \mathrm{~V}$, octopole RF Peak $750 \mathrm{~V}$; positive ion mode capillary voltage $3500 \mathrm{~V}$, corona positive $4.0 \mathrm{~V}$, fragmentor $175 \mathrm{~V}$, skimmer1 $65.0 \mathrm{~V}$ and octopole RF Peak $750 \mathrm{~V}$. Raw data were imported to Agilent MassHunter Qualitative Analysis B.06.00 software. Metabolites were identified by the in-house database.

\section{Nucleotide sequence numbers}

All of the nucleotide sequences of the bacterial isolates from this study have been deposited in the GenBank database under accession numbers KY436446-KY436504.

\section{Statistical analysis}

Metabolites were identified by the NIST database. Briefly, after alignment with Statistic Compare component, the CSV file was obtained with three-dimensional data-sets including sample information, peak name, retention time, $m / z$ and peak intensity. Internal standard peak and peaks caused by noise, column bleed and BSTFA derivatisation procedure, were removed from the data-set, and the peaks from the same metabolites were combined.

\section{Results}

\section{Isolation of rhizospheric and endophytic bacteria from halophytes}

In this study, three halophytes were collected from the coastal area of Thuwal, Jeddah (Fig. $\mathrm{S} 1$ ) and were identified as A. marina (mangrove), H. strobilaceum and $Z$. qatarense (Fig. S2(a-d)). The diversity of rhizospheric and endophytic was evaluated from soil, roots, leaves and pneumatophores of halophytes. A total of 554 colony-forming rhizospheric 
and endophytic bacteria were isolated from these three halophytes (Table 1). We have used five different culturing media for isolation of rhizopheric and endophytic bacteria were used. These different media that are in high and low nutrient contents favour different groups of bacteria to grow. Some of the bacterial colonies were so small and required 2-3 weeks to grow.

\section{Screening of bacteria against pathogenic fungi}

Rhizospheric and endophytic bacteria were tested for their antagonism against pathogenic oomycetes, Py. ultimum and P. capsici. Of 554 bacteria, 57 (10.2\%) displayed inhibition to both oomycete plant pathogens. The proportion of antagonistic bacteria varied, being highest in $A$. marina $(n=28 ; 12.3 \%)$ and $Z$. qatarense $(n=16 ; 11.8 \%)$, followed by $H$. strobilaceum $(n=13 ; 6.7 \%)$ (Table 1$)$. These antagonistic bacteria were then tested for other three fungal pathogens. Different groups of antagonistic rhizospheric and endophytic bacteria were identified from halophytes, where $\gamma$-Proteobacteria was the dominant phylum (Table 1). Antagonistic activity of all bacterial isolates is summarised in Table 2. Some strains showed strong inhibition with 7-9 mm against oomycetes pathogens. Among 57 antagonistic bacteria, only 4 (6.7\%), Alteromonas sp. (EA73) Streptomyces sp. (EA91), Bacillus sp. (EA115) and Halomonas sp. (EA127), exhibited inhibitory activity against all pathogenic fungi tested, whereas Bacillus sp. (EA78), Bacillus sp. (EA81), Mycobacterium sp. (EA84), Bacillus sp. (EA98) and Halomonas sp. (EA127) had strong inhibition only against oomycetes (Table 2). Some antagonistic bacteria were active against only oomycetes and were inactive for other pathogenic fungi used for screening in this study (Table 2). Halomonas was the dominant genus in this study among 30 different genera of antagonistic bacteria isolated from halophytes.

\section{Phylogenetic analysis of antagonistic bacteria based on 16S rRNA gene sequence}

Antagonistic bacteria $(n=57)$ were identified by using $16 \mathrm{~S}$ rRNA gene sequence analysis. Twenty different genera of bacteria were identified and belonged to five major classes: Actinobacteria $(n=12 ; 21 \%), \gamma$-Proteobacteria $(n=24 ; 42 \%)$, Firmicutes $(n=10 ; 18 \%)$, $\alpha$-Proteobacteria $(n=8 ; 14 \%)$, and Flavobacteriia $(n=3 ; 5 \%)$ (Figure 1$)$. The proportion of different genera in each part of plant sample and soil is shown in Figure $1(\mathrm{~b}-\mathrm{e})$. Sequence identity of antagonistic bacteria was from $92.8 \%$ to $100 \%$ (Table 2 ). The phylogenetic tree inferred using $16 \mathrm{~S}$ rRNA gene data showed that branching patterns remained constant. High bootstrap values were recorded in the phylogenetic tree using 16S rRNA

Table 1. Distribution of rhizospheric and endophytic antagonistic bacteria isolated from halophytes.

\begin{tabular}{lcccl}
\hline Plant species $^{\mathrm{a}}$ & Isolates $^{\mathrm{b}}$ & Antagonists $^{\mathrm{c}}$ & Antagonists $^{\mathrm{d}}$ (\%) & Dominant phylum $^{\mathrm{e}}$ \\
\hline Avicennia marina & 226 & 28 & 12.3 & Actinobacteria \\
Halocnemum strobilaceum & 193 & 13 & 6.7 & $\gamma$-Proteobacteria \\
Zygophyllum qatarense & 135 & 16 & 11.8 & $\gamma$-Proteobacteria \\
& 554 & 57 & 10.3 & $\gamma$-Proteobacteria \\
\hline
\end{tabular}

\footnotetext{
${ }^{a}$ Scientific names of halophytes collected from coastal area for isolation of bacteria.

'Total number of bacteria isolated from halophytes.

'Total number of antagonistic bacteria against $P$. capsici and Py. ultimum by confrontation bioassay.

dPercentage of antagonistic bacteria from total bacteria.

'Dominant phylum in all antagonistic bacteria to oomycetes.
} 
Table 2. Taxonomic identification, antifungal activity and enzymes production of rhizospheric and endophytic bacteria from halophytes.

\begin{tabular}{|c|c|c|c|c|c|c|c|c|c|c|c|c|c|c|c|}
\hline \multicolumn{9}{|c|}{ Antifungal activity against ${ }^{\mathrm{a}}$} & \multicolumn{4}{|c|}{ Enzymatic activities $^{b}$} & \multicolumn{3}{|c|}{ Detection of } \\
\hline $\begin{array}{l}\text { Lab } \\
\text { no }\end{array}$ & Closely related type strain ${ }^{d}$ & $\begin{array}{l}\text { Accession } \\
\text { number }\end{array}$ & $\stackrel{\%}{\%}$ identity $^{\mathrm{e}}$ & $\begin{array}{c}\text { Py. } \\
\text { ultimum }\end{array}$ & P. capsici & M. grisea & A. mali & F. moniforme & Protease & Amylase & Lipase & Cellulase & NRPS & $\begin{array}{c}\text { PKS- } \\
\text { I }\end{array}$ & $\begin{array}{c}\text { PKS- } \\
\text { II }\end{array}$ \\
\hline \multicolumn{16}{|c|}{ Avicennia marina } \\
\hline EA73 & Alteromonas australica $\mathrm{H} 17^{\top}$ & KY436446 & 98.6 & +++ & ++ & + & +++ & - & - & - & $\begin{array}{c}++++ \\
+\end{array}$ & - & - & - & - \\
\hline EA74 & Alteromonas madeodii ATCC $27126^{\top}$ & KY436447 & 98.7 & + & + & - & - & - & - & - & $\begin{array}{c}+++ \\
+\end{array}$ & - & - & - & - \\
\hline EA75 & Alteromonas australica $\mathrm{H} 17^{\top}$ & KY436448 & 97.3 & ++ & + & - & - & - & - & - & $\begin{array}{c}+++ \\
+\end{array}$ & - & - & - & - \\
\hline EA76 & $\begin{array}{l}\text { Pseudoalteromonas flavipulchra } \\
\text { NCIMB } 2033^{\mathrm{T}}\end{array}$ & KY436449 & 97.7 & ++ & + & - & - & - & - & - & - & - & - & - & - \\
\hline EA77 & Halomonas smymensis AAD6 ${ }^{\top}$ & KY436450 & 99.7 & + & + & - & - & - & - & - & - & - & - & - & - \\
\hline EA78 & Bacillus licheniformis ATCC $14580^{\top}$ & KY436451 & 99 & +++ & +++ & ++ & - & - & ++++ & +++++ & - & - & - & - & - \\
\hline EA79 & Halomonas denitrificans $\mathrm{M}_{2} 9^{\top}$ & KY436452 & 99.4 & + & +++ & - & - & - & - & - & - & - & - & - & - \\
\hline EA80 & Alteromonas gracilis $9 \mathrm{a} 2^{\top}$ & KY436453 & 92.8 & ++ & + & - & - & - & - & - & - & - & - & - & - \\
\hline EA81 & Bacillus persicus $\mathrm{B}^{4} 8^{\top}$ & KY436454 & 97.2 & +++ & +++ & - & - & - & - & - & - & - & - & - & - \\
\hline \multicolumn{16}{|c|}{ Endophytic bacteria (Pneumatophores) } \\
\hline EA82 & Devosia subaequoris HST3-14 ${ }^{\top}$ & KY436455 & 98.3 & ++ & W & - & - & - & - & - & ++++ & - & - & - & - \\
\hline EA83 & Nocardioides aromaticivorans $\mathrm{H}-1^{\top}$ & KY436456 & 99.4 & + & + & - & - & - & +++ & - & ++++ & - & + & - & - \\
\hline EA84 & $\begin{array}{l}\text { Mycobacterium wolinskyi ATCC } \\
700010^{\top}\end{array}$ & KY436457 & 99.9 & +++ & +++ & - & - & - & - & - & ++ & ++++ & + & - & - \\
\hline EA85 & Streptomyces spectabilis NBRC $13424^{\top}$ & KY436458 & 95.9 & + & ++ & - & - & - & - & - & - & - & + & + & + \\
\hline EA86 & Erythrobacter citreus RE35F/1 $1^{\top}$ & KY436459 & 98.2 & W & + & - & - & - & - & - & - & - & - & - & - \\
\hline EA87 & Nocardioides albus KCTC $9186^{\top}$ & KY436460 & 99.1 & ++ & + & - & - & - & $\begin{array}{c}++++ \\
+\end{array}$ & - & ++++ & - & & + & \\
\hline EA88 & Halomonas denitrificans $\mathrm{M}_{2} 9^{\top}$ & KY436461 & 99.2 & + & ++ & + & - & - & - & - & - & - & - & - & - \\
\hline EA89 & Nocardioides luteus KCTC $9575^{\top}$ & KY436462 & 100 & + & + & - & - & - & $\begin{array}{c}++++ \\
+\end{array}$ & - & +++ & - & - & - & - \\
\hline EA90 & Marinobacter mobilis $\mathrm{CN} 6^{\top}$ & KY436463 & 98.3 & + & ++ & + & - & - & - & - & - & - & - & - & - \\
\hline EA91 & $\begin{array}{l}\text { Streptomyces enissocaesilis NBRC } \\
100763^{\top}\end{array}$ & KY436464 & 100 & ++ & ++ & ++ & +++ & ++ & ++ & - & + & - & + & + & + \\
\hline \multicolumn{16}{|c|}{ Endophytic bacteria (Roots) } \\
\hline EA94 & Nocardioides luteus KCTC $9575^{\top}$ & KY436467 & 100 & ++ & W & - & - & - & - & - & - & - & - & - & - \\
\hline EA95 & Nocardioides albus KCTC $9186^{\top}$ & KY436468 & 96.8 & W & + & + & - & - & - & - & - & - & + & - & - \\
\hline EA96 & Nitratireductor shengliensis $110399^{\top}$ & KY436469 & 97.4 & ++ & + & + & ++ & - & - & - & - & - & - & - & - \\
\hline EA97 & Inquilinus limosus DSM $16000^{\top}$ & KY436470 & 96.4 & +++ & + & + & - & - & - & - & - & - & - & - & - \\
\hline EA98 & Bacillus beringensis $\mathrm{BR} 035^{\mathrm{T}}$ & KY436471 & 97.5 & +++ & +++ & - & - & - & - & - & - & - & - & - & - \\
\hline
\end{tabular}


EA99 Amycolatopsis thermalba $\mathrm{SF} 5^{\mathrm{T}}$

Endophytic bacteria (Leaf)

EA100 Micrococcus flavus LW4 ${ }^{\mathrm{T}}$

EA101 Brevibacterium casei NCDO $204^{\top}$

EA102 Staphylococcus epidermidis ATCC

$$
14990^{\top}
$$

Halocnemum strobilaceum

Rhizopheric bacteria (Soil)

EA103 Oceanicola litoreus M-M22

EA104 Roseisalinus antarcticus EL-88

EA105 Aidingimonas halophila YIM $90637^{\top}$

EA106 Halomonas anticariensis FP35 ${ }^{\mathrm{T}}$

EA107 Halomonas lutea DSM 23508

EA108 Halomonas smymensis AAD6

Endophytic bacteria (Roots)

EA109 Marinobacter lacisalsi FP2.5 ${ }^{\mathrm{T}}$

EA110 Bacillus timonensis MM10403188

EA111 Halomonas lutea DSM $23508^{\mathrm{T}}$

EA112 Salipiger mucosus DSM $16094^{\top}$

EA113 Rubrimonas diftonensis OCh $317^{\top}$

Leaf

EA114 Staphylococcus hominis subsp. novobiosepticus GTC $1228^{\top}$

EA115 Bacillus subtilis subsp. inaquosorum KCTC $13429^{\mathrm{T}}$

Zygophyllum qatarense

Rhizopheric bacteria (Soil)

EA116 Muricauda lutimaris SMK-108 ${ }^{\top}$

EA117 Tamlana crocina HST1-43

EA118 Marinimicrobium haloxylanilyticum SX15

EA119 Marinobacter salsuginis SD-14B

EA120 Halobacillus trueperi DSM 10404

EA121 Zunongwangia mangrovi P2E16 ${ }^{\top}$

Endophytic bacteria (Roots)

EA122 Marinobacter mobilis $\mathrm{CN}_{4} 6^{\top}$

EA123 Halomonas smymensis AAD6

EA124 Marinobacter lacisalsi FP2.5
KY436472

98.9

KY436473

KY436474

99.8

KY436475

99.3

99.5

$$
\begin{gathered}
+ \\
\text { W } \\
++
\end{gathered}
$$

KY436483

KY436484

KY436486 $\quad 92.9$

KY436487 99.7

KY436488

.9

KY436492

KY436493

97.3

KY436494

97.3
99.4

KY436495

$$
++
$$$$
++
$$$$
+
$$

$\begin{array}{cccc}+ & ++ & + & - \\ + & + & - & - \\ + & ++ & \mathrm{W} & - \\ & & & \\ ++ & +++ & + & - \\ ++ & +++ & - & - \\ + & + & - & - \\ + & ++ & ++ & - \\ + & + & + & - \\ + & ++ & - & -\end{array}$

$\begin{array}{ll}- & - \\ - & - \\ - & - \\ - & - \\ - & - \\ - & - \\ - & -\end{array}$

$\begin{array}{ll}- & \\ - & + \\ - & + \\ - & + \\ - & \\ - & \end{array}$

$\begin{array}{cc}- & ++ \\ ++ & - \\ - & - \\ ++ & - \\ - & - \\ - & + \\ - & - \\ - & +\end{array}$

$\begin{array}{cccccc}++ & ++++ & - & - & - & - \\ - & - & - & - & - & - \\ - & - & - & - & - & - \\ - & - & - & + & + & - \\ - & - & - & - & - & - \\ - & - & - & - & - & + \\ ++ & ++++ & - & + & - & + \\ - & - & - & + & - & - \\ + & & - & + & + & -\end{array}$


Table 2. Continued.

\begin{tabular}{|c|c|c|c|c|c|c|c|c|c|c|c|c|c|c|c|}
\hline \multicolumn{9}{|c|}{ Antifungal activity against ${ }^{\mathrm{a}}$} & \multicolumn{4}{|c|}{ Enzymatic activities $^{\mathrm{b}}$} & \multicolumn{3}{|c|}{ Detection of $^{f}$} \\
\hline $\begin{array}{l}\text { Lab } \\
\text { no }\end{array}$ & Closely related type strain ${ }^{d}$ & $\begin{array}{c}\text { Accession } \\
\text { number }\end{array}$ & $\begin{array}{c}\% \\
\text { identity }^{\mathrm{e}}\end{array}$ & $\begin{array}{c}\text { Py. } \\
\text { ultimum }\end{array}$ & P. capsici & M. grisea & A. mali & F. moniforme & Protease & Amylase & Lipase & Cellulase & NRPS & $\begin{array}{l}\text { PKS- } \\
1\end{array}$ & $\begin{array}{l}\text { PKS- } \\
\text { II }\end{array}$ \\
\hline & & & & & & & & & & & $\begin{array}{c}++++ \\
+\end{array}$ & & & & \\
\hline EA125 & Microbulbifer celer ISL-39 ${ }^{\top}$ & KY436498 & 99.3 & ++ & w & - & - & - & - & - & ++ & - & + & - & + \\
\hline EA126 & Bacillus licheniformis ATCC $14580^{\top}$ & KY436499 & 99.3 & ++ & +++ & ++ & + & - & ++++ & + & +++ & - & - & - & - \\
\hline $\begin{array}{l}\text { EA127 } \\
\text { Endoph }\end{array}$ & $\begin{array}{l}\text { Halomonas zincidurans } \mathrm{B}^{\mathrm{T}} \\
\text { hytic bacteria (Leaf) }\end{array}$ & KY436500 & 96.7 & +++ & +++ & + & + & +++ & - & - & - & - & - & - & - \\
\hline EA128 & $\begin{array}{l}\text { Arthrobacter crystallopoietes DSM } \\
20117^{\top}\end{array}$ & KY436501 & 97.3 & + & + & - & - & - & - & - & - & - & - & - & - \\
\hline EA129 & Halomonas smymensis AAD6 ${ }^{\top}$ & KY436502 & 99.7 & + & + & + & - & - & - & - & - & - & + & - & - \\
\hline EA130 & Staphylococcus warneri ATCC $27836^{\top}$ & KY436503 & 99.8 & ++ & ++ & - & - & - & - & - & +++ & - & - & - & - \\
\hline EA131 & Marinobacter algicola DG893 & KY436504 & 97.7 & ++ & ++ & ++ & - & - & - & - & +++ & - & + & - & - \\
\hline
\end{tabular}

antagonistic activity of all bacteria isolated in this study. The activity was measured after $3-5$ days incubation at $28^{\circ} \mathrm{C}$ by measuring the clear zone of mycelial growth inhibition: - , Negative; + , $3 \mathrm{~mm} ;++$, between 4 and $6 \mathrm{~mm} ;+++$, between 7 and $9 \mathrm{~mm}$

broduction of protease, amylase, lipase and cellulase was determined by plate assay. Enzymatic activity was estimated as zone of halo formed around bacterial colonies:,- Negative;,+ 3 mm; ++ , between 4 and $6 \mathrm{~mm} ;+++$, between 7 and $9 \mathrm{~mm} ;++++$, between 10 amd $12+++++$, between 13 and 15 .

'Detection of NRPS and PKS-I and PKS-II genes in antagonistic bacteria.

Identification based on partial 16S rRNA gene sequence analyses of all antagonistic bacteria.

$\%$ similarity with closely related type strain 


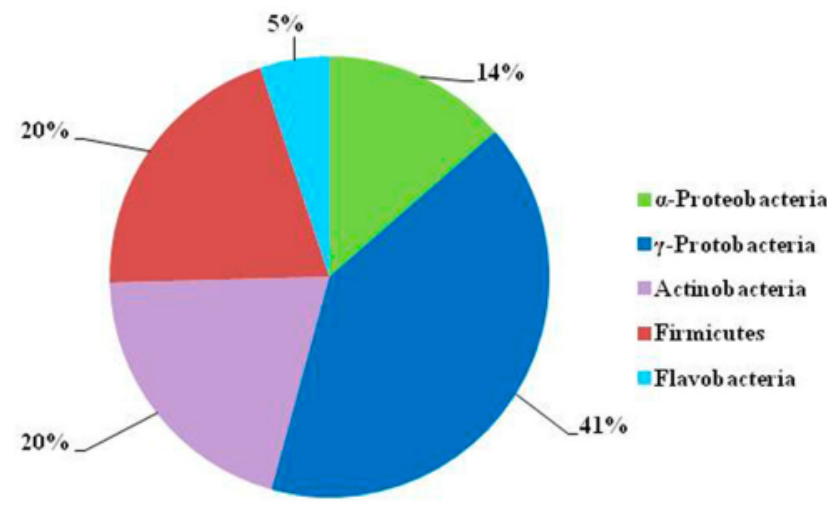

(a)

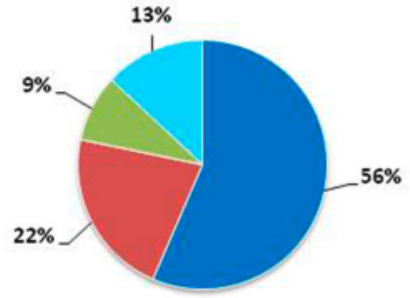

(b)

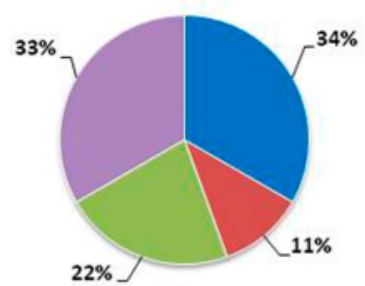

(c)

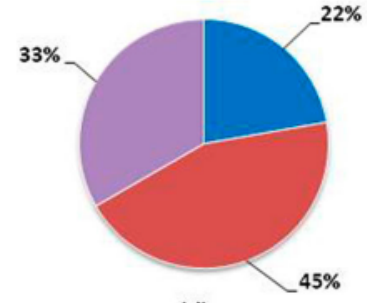

(d)

Figure 1. (a) Percentage composition of different phyla of antagonistic rhizospheric and endophytic bacteria isolated from four halophytes on the basis of $16 \mathrm{~S}$ rRNA gene sequence similarity. Percentage composition of different phyla in (b) soil, (c) roots, (d) leaves and (e) pneumatophores.

gene sequences data (Figure 2). Antagonistic strains of class Firmicutes were placed in a separate cluster recovered with higher bootstrap values. Antagonistic bacteria in Firmicutes mainly belonged to the genera Bacillus, Staphylococcus and Halobacillus. Three different clusters have been generated for isolates of class Actinobacteria. Antagonistic bacteria in these three clusters were identified with high bootstraps values (54-100\%). Representative isolates in this class belong to four different genera, i.e. Nocardioides, Arthrobacter, Streptomyces and Mycobacterium. Three strains of Flavobacteriia were identified with a separate cluster also showing high bootstrap values (64-100\%). The strains of $\alpha$-Proteobacteria comprising eight different genera were placed in one cluster in the phylogenetic tree with high bootstrap values. The representative strains of $\gamma$-Proteobacteria belong to five different genera. All strains of the genus Halomonas make a distinct cluster with the closely related type strain Halomonas denitrificans $\mathrm{M} 29^{\mathrm{T}}$ with a bootstrap value of $99-100 \%$. In this study, some novel and new antagonistic rhizospheric and endophytic bacterial strains were also identified in addition to common and already known bacteria (Table 2). Some antagonistic rhizospheric and endophytic bacteria were recovered showing low $16 \mathrm{~S}$ rRNA gene sequence similarity (<95\%). Two isolates of $\alpha$-Proteobacteria, i.e. Roseisalinus sp. (EA104) and Rubrimonas sp. (EA113), and one isolate belonging to $\gamma$ Proteobacteria, i.e. Alteromonas sp. (EA80), were identified as novel species with similarities of $<95 \%$ to the closest type strains in GenBank (Table 2). In addition to these novel isolates, many other novel antagonistic rhizospheric and endophytic bacteria 


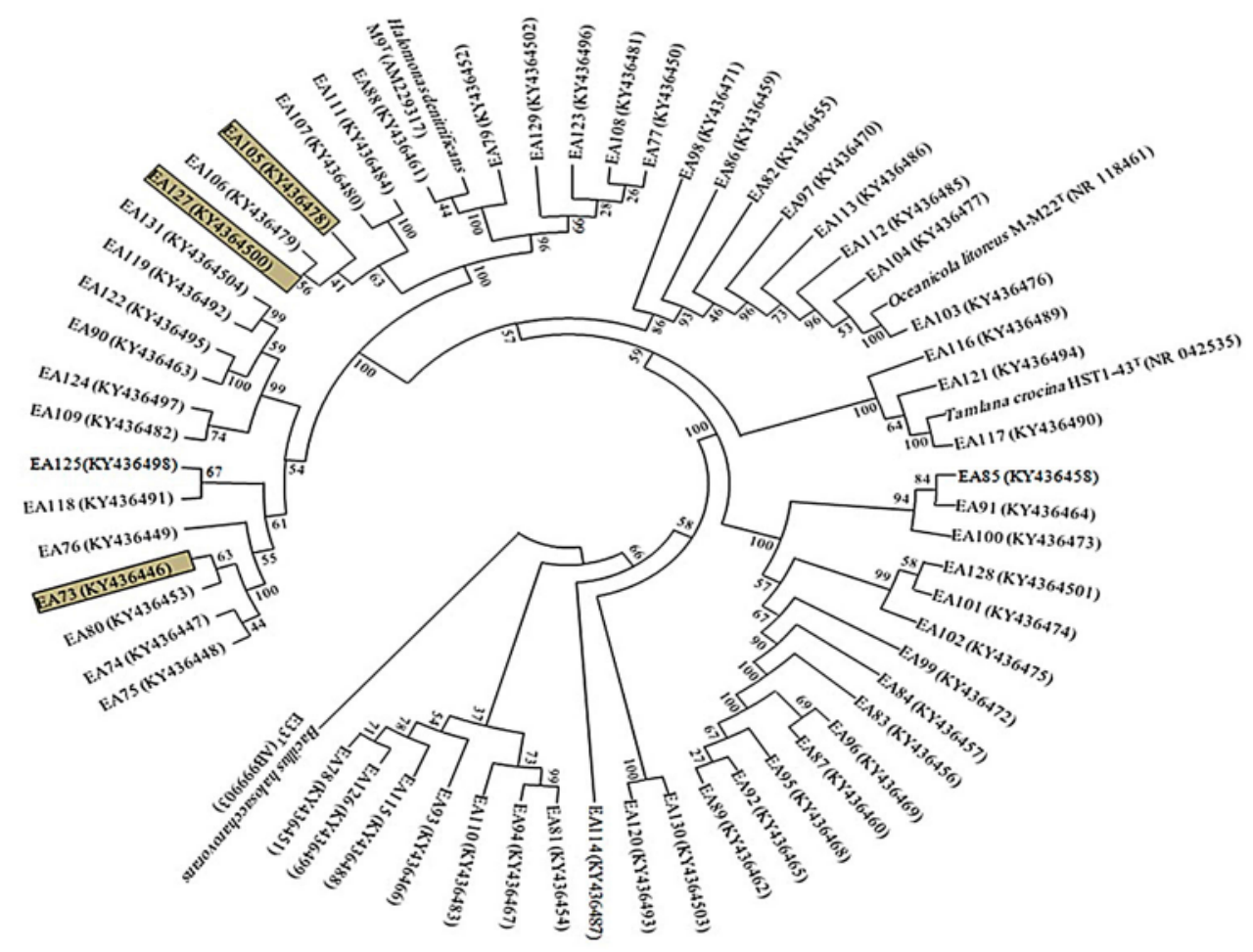

Figure 2. Phylogenetic distribution of antagonistic bacteria isolated from halophytes on the basis of $16 S$ rRNA gene sequences obtained from bacteria and dosely related sequences of the type strains of other species. The phylogenetic relationships were inferred from the 16S rRNA gene by using the neighbour-joining method from distances computed with the Jukes-Cantor algorithm. Bootstrap values (1000 replicates) are shown next to the branches. GenBank accession numbers for each sequence are shown in parentheses. Bar represents 0.01 accumulated changes per nucleotide. Isolates selected for bioactive metabolites identification are highlighted.

belonging to different genera were identified in this study. More potential antagonistic candidates have been identified from the class $\gamma$-Proteobacteria. Some strains of $\gamma$-Proteobacteria with high antagonistic activity against pathogenic fungi were common and had a sequence similarity of $100 \%$ with the relative type strain. Alteromonas sp. (EA73), Aidingimonas sp. (EA105) and Halomonas sp. (EA127) and had moderate to strong inhibitory activity and were identified as novel strains with sequence similarity of $98.6 \%, 97.8 \%$ and $96.7 \%$, respectively, with relative type strains. We have selected these three antagonistic strains depending on their $16 \mathrm{~S}$ rRNA sequence similarity and antagonistic activity for secondary metabolite identification.

\section{Enzymatic activities of antagonistic bacteria}

Antagonistic rhizospheric and endophytic bacteria were evaluated for their ability to produce cell wall lytic enzymes. We have tested protease, amylase, lipase and cellulase activities (Table 2). The number of antagonistic rhizospheric and endophytic bacteria exhibiting lipase activity $(n=19 ; 32 \%)$ was high as compared to other enzymatic activities. 
Most of lipase-producing bacteria were endophytes $(n=17)$ and were isolated from leaves and root tissues of halophytes. Three rhizospheric bacteria, strains EA73-EA75 belonging to Alteromonas, displayed high lipase activity (Table 2). Protease production was observed lower $(n=8 ; 13.5 \%)$ than lipase activity. Most of the endophytes $(n=5)$ were potential protease enzyme producers. Mostly Actinobacteria and Firmicutes strains were recorded for high protease production. Strains of Bacillus sp. (EA78), Nocardioides sp. (EA87), Nocardioides sp. (EA89) and Bacillus sp. (EA126) had strong protease production. Amylase activity was recorded for 6 (10\%) antagonistic bacteria. Most of the bacterial strains with strong amylase activity are species of the class Firmicutes. Endophytic strain of Bacillus sp. (EA78) exhibited high production of amylase. Cellulase production was observed in only 1 (1.6\%) bacterial strains. A strain of Mycobacterium sp. (EA84) exhibited cellulase production and it belongs to Actinobacteria. Some antagonistic strains were negative $(n=24 ; 40.6 \%)$ for production of all tested enzyme activities.

\section{Detection of NRPS and PKS-I systems}

All antagonistic bacterial isolates were subjected to genetic screening for the presence of NRPS and PKS genes. Of 57 isolates tested, PCR amplification revealed that 21 strains $(36.8 \%)$ were positive for at least one of the biosynthetic gene tested (Table 2). And for the NRPS gene, 18 (31\%) strains were positive. Most of the strains were positive for NRPS genes and belonged to the class Actinobacteria. For the gene PKS-I, only 7 (12\%) antagonistic bacterial strains were positive. Similarly, PKS-II gene cluster was detected in only $9(15.2 \%)$ strains. Both these genes PKS-I and PKS-II were mostly detected in the strains of Actinobacteria. Three bacterial isolates, Erythrobacter sp. (EA85), Streptomyces sp. (EA91) and Halomonas sp. (EA106), in this study possess all of the biosynthetic genes (NRPS, PKS-I and PKS-II). Two isolates belonging to $\gamma$-Proteobacteria, Marinobacter sp. (EA119) and Marinobacter sp. (EA124), showed the presence of both NRPS and PKS-I genes. Similarly, two isolates of Actinobacteria, Amycolatopsis sp. (EA99) and Brevibacterium sp. (EA101), were positive for the presence of both NRPS and PKS-II system.

\section{Culture condition optimisation and identification of metabolites by GC-MS and LC-MS}

In all tested media, $1 / 2 \mathrm{R} 2 \mathrm{~A}$ broth was found to be the best culturing media. Selected strains showed the best growth at $\mathrm{pH} 7.5$ and $28^{\circ} \mathrm{C}$ in the shaking incubator (140 rpm). After optimisation of conditions, selected bacterial strains were grown in $5 \mathrm{~mL} 1 / 2 \mathrm{R} 2 \mathrm{~A}$ broth in seawater for $36-48 \mathrm{~h}$ until $\mathrm{OD}_{600}$ reached 0.9 . From these 57 antagonistic bacteria, only 3 antagonistic isolates were selected belonging to the class $\gamma$-Proteobacteria, i.e. Alteromonas sp. (EA73), Aidingimonas sp. (EA105) and Halomonas sp. (EA127) due to their low sequence similarity and high antifungal activity. GC-MS and LC-MS analyses of culture of these three strains identified different chemical constituents (Figures 3(a-c) and 4(a-e)). For GC-MS, different chemical compounds were identified by comparing their mass spectra with the NIST library. Isolate Alteromonas sp. (EA73) exhibited the presence of bioactive compounds like aminoguanidine, styramate, azetidine and cyacetacide (Figure 3(a)) 

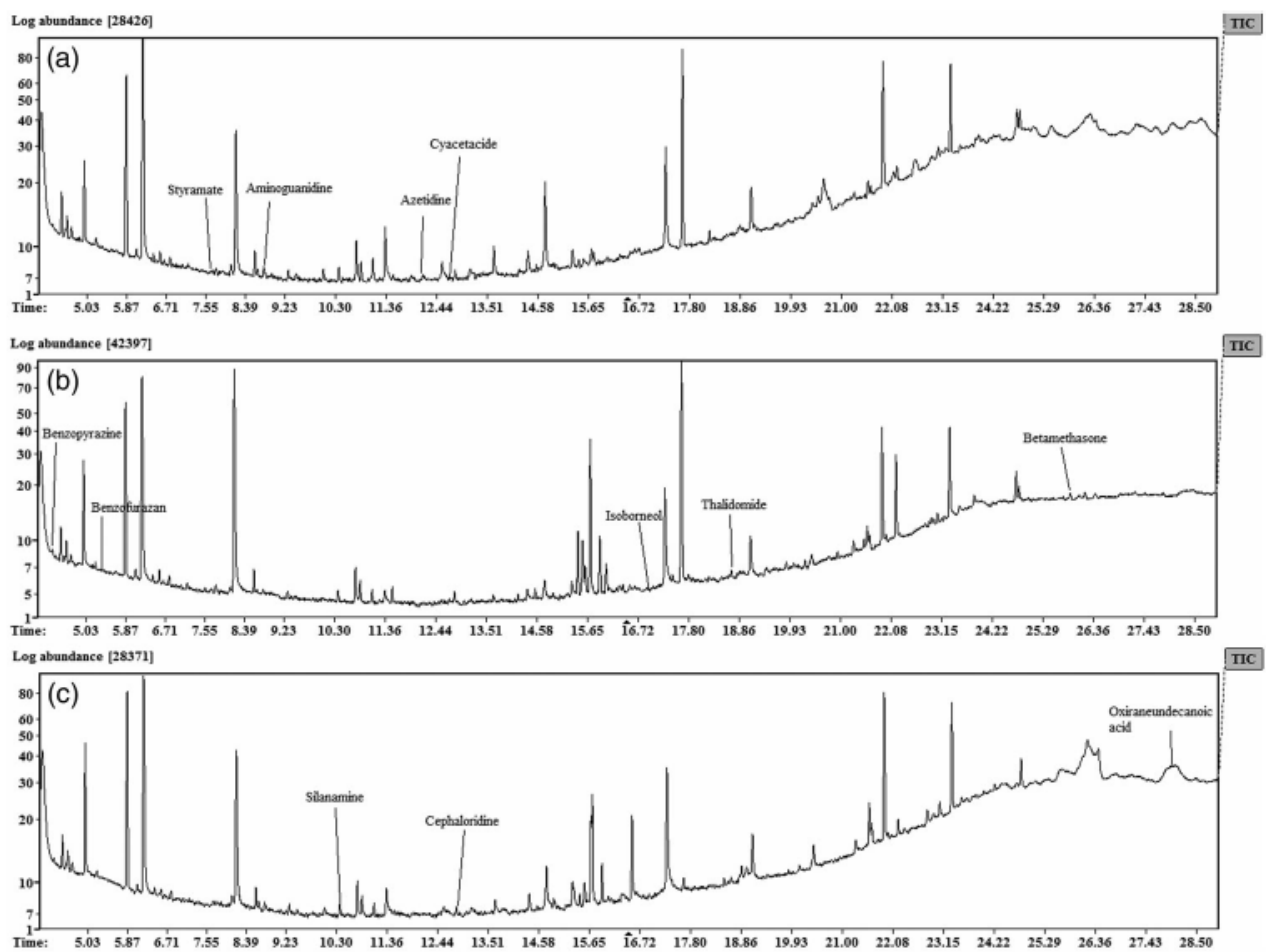

Figure 3. Bioactive compounds detected by GC-MS analysis. (a) GC-MS spectra of Alteromonas sp. (EA73), (b) Aidingimonas sp. (EA105) and (c) Halomonas sp. (EA127).

which have been already known for their use in the pharmaceutical industry (Harrington, 2011). The culture extract of strain Aidingimonas sp. (EA105) showed the presence of chemical compounds of biological significance such as benzopyrazine, benzofurazan, isoborneol, betamethasone borneol and thalidomide valerate (Figure 3(b)). Chemical analyses of Halomonas sp. (EA127) resulted in the identification of different active metabolites namely silanamine, cephaloridine and oxiraneundecanoic (Figure 3(c)).

LC-MS analysis was performed to identify metabolites from culture extract. LC-MS analysis of Alteromonas sp. (EA73) identified peaks for only nine secondary metabolites in both the positive- and negative-ion mode (Figure $4(\mathrm{a}, \mathrm{b})$ ). These compounds include DAPG, methyl jasmonate, prednicarbate, methoxamedrine, benzydamine, 5-formylsalicylic acid, geranylgeraniol, stearamide and erucamide. For Aidingimonas sp. (EA105), 26 different peaks were identified where 4 active compounds including allopurinol, trigonelline, triamcinolone acetone and dodecanedioic acid were detected in the negative-ion mode (Figure 4(c)). Halomonas sp. (EA127) showed the presence of four bioactive compounds in their culture extract, i.e. DAPG, benzydamine and dodecanedioic acid (Figure 4 $(\mathrm{d}, \mathrm{e}))$. In this study, the antibiotic DAPG is produced by two strains Alteromonas sp. (EA73) and Halomonas sp. (EA127) that is already known for its antiphytopathogenic and biocontrol properties. 

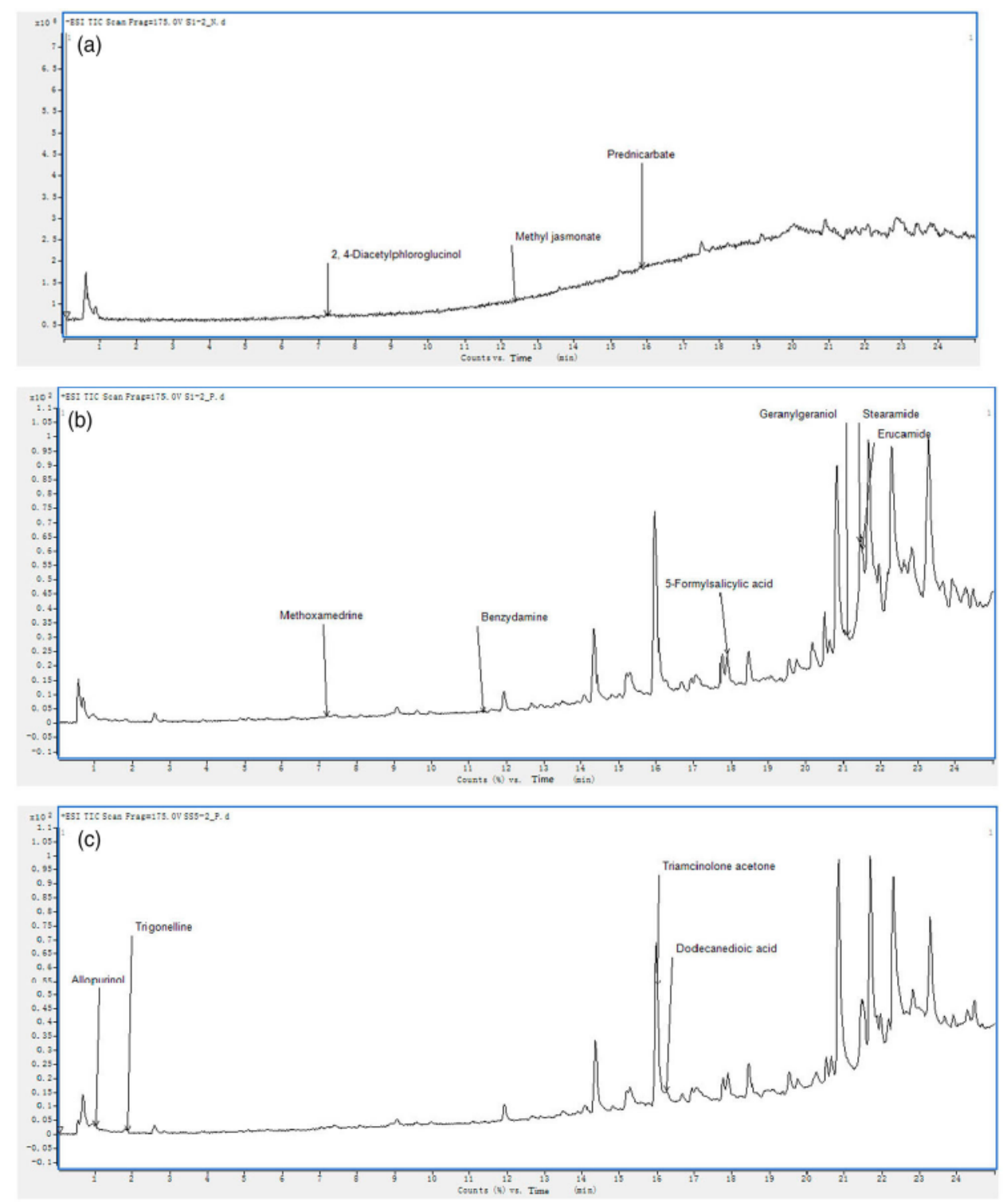

Figure 4. Spectra of LC-MS analysis showing detection of various bioactive metabolites. Alteromonas sp. (EA73) (a) Positive mode LC-MS analysis and (b) negative mode LC-MS analysis; (c) Negative mode Aidingimonas sp. (EA105) LC-MS analysis; (d) Halomonas sp. (EA127) Positive mode and (e) negative mode LC-MS analysis.

\section{Discussion}

Halophytes exist under extreme environmental conditions which lead to the production of certain metabolites enabling them to survive under these harsh conditions (De Carvalho \& Fernandes, 2010). In this study, we have isolated 57 different antagonistic bacteria active against different common fungal pathogens. For the isolation of bacteria, we used four 
(d)
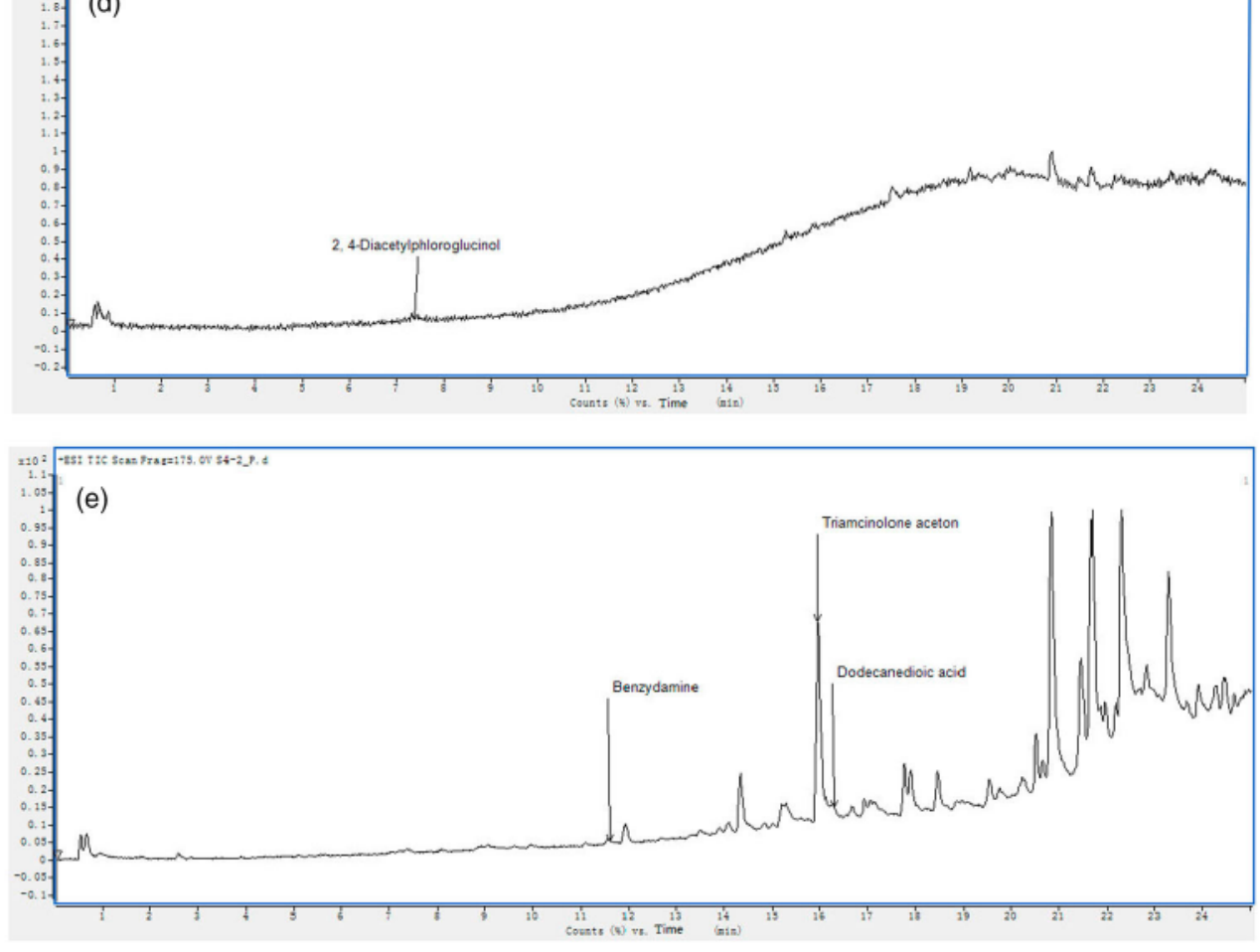

Figure 4. Continued

different types of media in low nutrient concentration which results in the isolation of diverse groups of antagonistic bacteria. We have also used this methodology in our previous studies and this has resulted in the isolation of many novel isolates with unique bioactivities (Bibi et al., 2012, 2017). To our knowledge, this is the first study on the isolation, screening, characterisation and metabolite identification of rhizospheric and endophytic bacteria from halophytes in Saudi Arabia.

In this study, we have used a culture-dependent approach to explore the diversity of antagonistic rhizospheric and endophytic bacteria. Screening of 554 rhizospheric and endophytic bacteria against oomycetes and identification on the basis of 16S rRNA gene sequence resulted in the identification of 57 different bacteria comprising five major classes. Bioactive compounds production by rhizospheric and endophytic bacteria is one of the techniques used by bacteria to defend the host against different pathogens (Coombs, Michelsen, \& Franco, 2004). Several previous studies have reported the production of antimicrobial compounds by bacteria isolated from mangrove plants (Eldeen \& Effendy, 2013; Hu et al., 2010). We have isolated a high number of species of antagonistic rhizospheric and endophytic bacteria from these plants. High percentage of antagonistic bacteria may be resulted as different culturing media, isolation source (soil, roots and leaves) and only oomycetes pathogens as target organisms were used for screening. Some previous studies reported the final limited outcome of bacterial diversity when only soil was used as a microbial isolation source (Mitra, Santra, \& Mukherjee, 2008; Rameshkumar \& Nair, 2009). Most of the antagonistic bacteria were recovered from the root $(n=27 ; 46 \%)$ tissue samples. Similarly, the 
number of antagonistic bacteria was higher in soil $(n=23 ; 39 \%)$ as compared to leaf tissues $(n=9 ; 15 \%)$ (Figure 1(b-d)). The importance of endophytes from mangrove plants has been previously reported (Eldeen \& Effendy, 2013; Menpara \& Chanda, 2013), and in our study, endophytes exhibited strong antagonistic activities against different fungal pathogens. These bacterial endophytes belong to genus Bacillus and can be considered as potential candidates for use as biocontrol agents.

Identification of these antagonistic bacteria based on the 16S rRNA gene resulted in five major classes of bacteria. Phylogenetic analysis yielded a tree topology that grouped all antagonistic rhizospheric bacteria and endophytic into five different groups: Actinobacteria (Nocardioides, Arthrobacter, Streptomyces, Mycobacterium), $\gamma$-Proteobacteria (Alteromonas, Pseudoalteromonas, Halomonas, Marinobacter, Aidingimonas), Firmicutes (Bacillus, Staphylococcus, Halobacillus), $\alpha$-Proteobacteria (Devosia, Erythrobacter, Nitratireductor, Inquilinus, Oceanicola, Aidingimonas, Salipiger, Rubrimonas), and Flavobacteriia (Muricauda, TamLana, Zunongwangia) (Figure 1 and 2). Some genera were represented by several species in these halophytes while some other genera were represented by only single species. Our results demonstrated that class $\gamma$-Proteobacteria was dominant (41\%) among all the antagonistic bacterial communities isolated from four different halophytes (Tables 1 and 2). In this study, five different genera of $\gamma$-Protobacteria (Pseudomonas, Alteromonas, Pseudoalteromonas, Halomonas, Marinobacter, Aidingimonas) were isolated. Among Gram-negative marine bacteria, $\gamma$-Proteobacteria produced the highest number of secondary metabolites with functional diversity (Long \& Azam, 2001). In this study, we also choose isolates Alteromonas sp. (EA73), Aidingimonas sp. (EA105) and Halomonas sp. (EA127) belong to $\gamma$-Proteobacteria for secondary metabolite identifications.

The second dominant class of bacteria was Actinobacteria (20\%) and Firmicutes (20\%). Today, the marine actinomycetes are considered as a major source for discovery of novel natural products. Marine Actinobacteria are a source of novel antimicrobial compounds, many of them such as salinosporamides are in clinical trials for use as anticancer agents (Fenical \& Jensen, 2006). Previously, different strains of Actinobacteria isolated from mangrove sediments showed antimicrobial activity against different human pathogenic bacteria (Lee et al., 2014). In this study, most of the antagonistic rhizospheric and endophytic bacteria belonging to the class Actinobacteria in this study such as Nocardioides, Arthrobacter, Pseudonocardia, Streptomyces, Agromyces and Mycobacterium are already known for their antagonism and production of antimicrobial metabolites (Fenical \& Jensen, 2006). Bacteria belonging to class Firmicutes are commonly found both as rhizospheric and endophytic bacteria as they are easily cultivated. In marine environments, strains of Bacillus are the dominant producers of antibacterial, antifungal antibiotics, enzymes and surfactants (Mondol, Shin, \& Islam, 2013). The representative of Firmicutes in our study belonged to Bacillus, Staphylococcus and Halobacillus species are already known to produce antifungal substances (Wagner-Döbler, Beil, Lang, Meiners, \& Laatsch, 2002). Previously two endophytic bacterial strains of Bacillus were isolated from mangrove plants and showed inhibition against bacterial and fungal plant pathogens (Menpara \& Chanda, 2013). In this study, 14\% antagonistic rhizospheric and endophytic bacteria were related to class $\alpha$-Proteobacteria including eight different genera. Several strains of $\alpha$-Proteobacteria isolated from marine sources live in symbiosis and nitrogen fixers, and produce antibiotics (Castro et al., 2014; Wagner-Döbler et al., 2002). In this study, three strains of Flavobacteriia were isolated from soil samples 
adhering roots of host halophyte, $Z$. qatarense. Two antagonistic strains of Flavobacteriia, Muricauda sp. (EA116) and Marinimicrobium sp. (EA118) seems novel based on their 16S rRNA similarity to related type strains.

Marine bacteria are already known for the production of different hydrolytic enzymes exhibiting diverse enzymatic activities and catalysing different biochemical processes using these enzymes (Thatoi et al., 2013). Most of the bacteria in our study produced lipase, protease and amylase enzymes. Only two strains were found positive for production of cellulase. Mostly Actinobacteria and Firmicutes strains were able to produce different enzymes. Bacillus sp. (EA126) showed protease, amylase and lipase activity. This strain is endophytic and isolated from roots of halophyte $Z$. qatarense. These hydrolytic enzymes are necessary for antagonism as well as for intracellular colonisation of bacteria to host plant. Castro et al. (2014) have evaluated mangrove plants for isolation and screening of bacteria for enzymatic activities. They found different groups of endophytic enzymatic bacteria where Firmicutes was the dominant class consistent with our study.

Marine bacteria possess PKS and NRPS genes which are hallmarks for the production of secondary metabolites. Of 57 isolates tested for PKS-I, PKS-II and NRPS gene, only 12\% were positive for PKS-I, 15\% for PKS-II and 31\% for NRPS genes. Mostly strains of Actinobacteria were positive for the presence of PKS-I and PKS-II genes. Two endophytic isolates, Streptomyces sp. (EA85) and Streptomyces sp. (EA91), and one rhizospheric bacteria, Halomonas sp. (EA106), possess all of the biosynthetic genes (NRPS, PKS-I and PKS-II) tested. The PCR-based detection of PKS-I, PKS-II and NRPS genes is important in screening and identification of bacterial isolates capable of producing active secondary metabolites. In our study, some isolates including three strains chosen for chemical analysis were negative for amplification of these genes and may be due to the use of degenerate primers which were not suitable for these genes (Qin et al., 2009; Qin, Li, Dastager, \& Hozzein, 2016; Salomon, Magarvey, \& Sherman, 2004). Detection of PKS-I and PKS-II genes was high in strains of Actinobacteria, providing a confirmation for the high possibility of Actinobacteria producing active secondary metabolites.

The antifungal potential of selected isolates was influenced by culturing in R2A as culture media using optimum culture conditions. The maximum antifungal activity was observed after $48 \mathrm{~h}$ of growth at $28^{\circ} \mathrm{C}$ with $\mathrm{pH}$ 7.5. Three selected Gram-negative bacteria belong to class $\gamma$-Proteobacteria were analysed using LC-MS and GC-MS for secondary metabolites present in their culture extract. We used LC-MS in addition to GC-MS as LC technique mainly focuses on polar metabolites (especially phosphate-containing compounds), most of which cannot be analysed using GC-MS. Both analyses confirm the presence of various bioactive compounds, although not novel but already known for their bioactivity. The antibiotic DAPG was detected in two isolates Alteromonas sp. (EA73) and Halomonas sp. (EA127) culture extracts when analysed by LC-MS. DAPG is an antibiotic with broad-spectrum antibacterial and antifungal activities produced by Pseudomonas fluorescens strain that has been used as a biocontrol agent against several plant pathogens including Py. ultimum (Delany et al., 2000) which is also a test pathogen in our study. Both these strains, Alteromonas sp. (EA73) and Halomonas sp. (EA127), showed strong inhibition against $P y$. ultimum in an in vitro assay when we tested. Detection of DAPG in both these strains suggests its role in these bacteria as an antifungal agent against tested pathogens. Members of genus Alteromonas usually associated with marine sponges produce compounds such as a macrolactam and amide ester with cytotoxic and 
antimicrobial activity (Thomas, Kavlekar, \& LokaBharathi, 2010). Similarly, strains of Halomonas from a marine source are able to produce siderophore, Loihichelins (Giddings \& Newman, 2015). But no previous study has reported the production of DAPG by marine strains of these two genera. Alteromonas sp. (EA73) also showed the presence of some anti-inflammatory compounds such as prednicarbate and benzydamine are used as drugs where benzydamine has antibacterial activity (Fanaki \& El-Nakeeb, 1992). In addition to these compounds, methyl jasmonate, volatile compounds produced by plants as a defence mechanism (Gimenez-Ibanez, Chini, \& Solano, 2016), were also detected in Alteromonas sp. (EA73) culture extract. Aminoguanidine and styramate have medical uses in diabetic and anticonvulsant drugs, respectively, were also detected. No such compound has been reported previously in strains of Alteromonas.

Cephaloridine is a semisynthetic cephalosporin antibiotic, and was detected in Aidingimonas sp. (EA105). This derivative of cephalosporin $\mathrm{C}$ is used in respiratory tract infections. This is first report of cephaloridine detection in bacteria. Aidingimonas sp. (EA105) was also able to produce benzydamine in addition to triamcinolone acetonide and dodecanedioic acid. Triamcinolone acetonide is synthetic corticosteroid and used in various skin infections while dodecanedioic acid has various industrial uses. Like Aidingimonas sp. (EA105), triamcinolone acetonide and dodecanedioic acid also were detected in Halomonas sp. (EA127). Furthermore, Halomonas sp. (EA127) also exhibited production of allopurinol and thalidomide valerate which have their use in pharmaceutical industry. According to LC-MS and GC-MS analyses, all compounds detected in these three selected strains have their medicinal use and are reported as anti-inflammatory, antibacterial and antifungal compounds. These compounds seem to be responsible for antifungal activities of these three strains.

\section{Conclusions}

In this study, 57 antagonistic rhizospheric and endophytic bacteria inhabiting halophytes have been isolated and partially characterised. Among all, 21 bacterial strains have at least one type of biosynthetic gene cluster, indicating their importance and potential for discovery of new bioactive compounds. Moreover, these antagonistic bacteria exhibited enzymatic activities indicating their industrial and biotechnological potential. Analyses of selected potential strains exhibited the presence of various bioactive metabolites including known antibiotics and bioactive compounds of synthetic nature not reported from bacteria before. These results suggest that halophytes are a potential source of unexplored metabolites. Antagonistic bacteria from halophytes growing in the coastal area of the Red Sea in Saudi Arabia have the potential to produce a diverse range of antimicrobial compounds that can be used in medicine and as a biocontrol agent in agriculture.

\section{Disclosure statement}

No potential conflict of interest was reported by the authors.

\section{Funding}

This project was funded by the National Plan for Science, Technology and Innovation (MAARIFAH)-King Abdulaziz City for Science and Technology, the Kingdom of Saudi Arabia (award 
number 12-BIO-2724-03). The authors also acknowledge with thanks the Science and Technology Unit, King Abdulaziz University for technical support.

\section{ORCID}

Fehmida Bibi (D) http://orcid.org/0000-0002-5178-1471

\section{References}

Alzubaidy, H., Essack, M., Malas, T. B., Bokhari, A., Motwalli, O., Kamanu, F. K., ... Archer, J. A. C. (2016). Rhizosphere microbiome metagenomics of gray mangroves (Avicennia marina) in the Red Sea. Gene, 576, 626-636.

Ayuso-Sacido, A., \& Genilloud, O. (2005). New PCR primers for the screening of NRPS and PKS-I systems in actinomycetes: Detection and distribution of these biosynthetic gene sequences in major taxonomic groups. Microbial Ecology, 49, 10-24.

Bandaranayake, W. M. (2002). Bioactivities, bioactive compounds and chemical constituents of mangrove plants. Wetlands Ecology and Management, 10, 421-452.

Bibi, F., Ullah, I., Alvi, S. A., Bakhsh, S. A., Yasir, M., Al-Ghamdi, A. A. K., \& Azhar, E. I. (2017). Isolation, diversity, and biotechnological potential of rhizo and endophytic bacteria associated with mangrove plants from Saudi Arabia. Genetics and Molecular Research, 16(2). doi:10.4238/gmr16029657

Bibi, F., Yasir, M., Song, G. C., Lee, S. Y., \& Chung, Y. R. (2012). Diversity and characterization of endophytic bacteria associated with tidal flat plants and their antagonistic effects on oomycetous plant pathogens. The Plant Pathology Journal, 28, 20-31.

Castro, R. A., Quecine, M. C., Lacava, P. T., Batista, B. D., Luvizotto, D. M., Marcon, J. ... Azevedo, J. L. (2014). Isolation and enzyme bioprospection of endophytic bacteria associated with plants of Brazilian mangrove ecosystem. SpringerPlus, 3, 382.

Chandrasekaran, M., Kannathasan, K., Venkatesalu, V., \& Prabhakar, K. (2009). Antibacterial activity of some salt marsh halophytes and mangrove plants against methicillin resistant Staphylococcus aureus. World Journal of Microbiology and Biotechnology, 25, 155-160.

Chung, B. S., Aslam, Z., Kim, S. W., Kim, G. G., Kang, H. S., Ahn, J. W., \& Chung, Y. R. (2008). A bacterial endophyte, Pseudomonas brassicacearum YC5480, isolated from the root of Artemisia sp. producing antifungal and phytotoxic compounds. The Plant Pathology Journal, 24, 461-468.

Coombs, J. T., Michelsen, P. P., \& Franco, C. M. (2004). Evaluation of endophytic actinobacteria as antagonists of Gaeumannomyces graminis var. tritici in wheat. Biological Control, 29, 359-366.

De Carvalho, C. C., \& Fernandes, P. (2010). Production of metabolites as bacterial responses to the marine environment. Marine Drugs, 8, 705-727.

Delany, I., Sheehan, M. M., Fenton, A., Bardin, S., Aarons, S., \& O'Gara, F. (2000). Regulation of production of the antifungal metabolite 2,4-diacetylphloroglucinol in pseudomonas fluorescens F113: Genetic analysis of phlF as a transcriptional repressor. Microbiology, 146, 537-546.

Eldeen, I. M., \& Effendy, M. A. (2013). Antimicrobial agents from mangrove plants and their endophytes. In A. Méndez-Vilas (Ed.), Microbial pathogens and strategies for combating them: Science, technology and education (pp. 872-882). FORMATEX Microbiology Book Series. Badajoz: Formatex Research Centre.

Fanaki, N. H., \& El-Nakeeb, M. A. (1992). Antimicrobial activity of benzydamine, a non-steroid anti-inflammatory agent. Journal of Chemotherapy, 4, 347-352.

Fenical, W., \& Jensen, P. R. (2006). Developing a new resource for drug discovery: Marine actinomycete bacteria. Nature Chemical Biology, 2, 666-673.

Garcias-Bonet, N., Arrieta, J. M., de Santana, C. N., Duarte, C. M., \& Marbà, N. (2012). Endophytic bacterial community of a Mediterranean marine angiosperm (Posidonia oceanica). Frontiers in Microbiology, 3, 1-16.

Giddings, L. A., \& Newman, D. J. (2015). Bioactive compounds from marine extremophiles. In Bioactive compounds from marine extremophiles (pp. 1-124). Heidelberg: Springer International Publishing. 
Gimenez-Ibanez, S., Chini, A., \& Solano, R. (2016). How microbes twist jasmonate signaling around their little fingers. Plants, 5, 9.

Hall, T. (1999). Bioedit: A user-friendly biological sequence alignment editor and analysis program for Windows 95/98/NT. Nucleic Acids Symposium Series, 41, 95-98.

Harrington, P. J. (2011). Pharmaceutical process chemistry for synthesis: Rethinking the routes to scale-up. Hoboken, NJ: John Wiley \& Sons.

Hendricks, C. W., Doyle, J. D., \& Hugley, B. (1995). A new solid medium for enumerating celluloseutilizing bacteria in soil. Applied and Environmental Microbiology, 61, 2016-2019.

$\mathrm{Hu}, \mathrm{H}$. Q., Li, X. S., \& He, H. (2010). Characterization of an antimicrobial material from a newly isolated Bacillus amyloliquefaciens from mangrove for biocontrol of capsicum bacterial wilt. Biological Control, 54, 359-365.

Jose, A. C., \& Christy, P. H. (2013). Assessment of antimicrobial potential of endophytic bacteria isolated from Rhizophora mucronata. International Journal of Current Microbiology and Applied Science, 2, 188-194.

Kim, O. S., Cho, Y. J., Lee, K., Yoon, S. H., Kim, M., Na, H., ... Won, S. (2012). Introducing EzTaxon-e: A prokaryotic 16S rRNA gene sequence database with phylotypes that represent uncultured species. International Journal of Systematic and Evolutionary Microbiology, 62, 716-721.

Kumar, S., Karan, R., Kapoor, S., Singh, S. P., \& Khare, S. K. (2012). Screening and isolation of halophilic bacteria producing industrially important enzymes. Brazilian Journal of Microbiology, 43, 1595-1603.

Lee, L. H., Zainal, N., Azman, A. S., Eng, S. K., Goh, B. H., Yin, W. F., \& Chan, K. G. (2014). Diversity and antimicrobial activities of actinobacteria isolated from tropical mangrove sediments in Malaysia. Scientific World Journal, 2014, 698178.

Long, R. A., \& Azam, F. (2001). Antagonistic interactions among marine pelagic bacteria. Applied and Environmental Microbiology, 67, 4975-4983.

Menpara, D., \& Chanda, S. (2013). Endophytic bacteria-unexplored reservoir of antimicrobials for combating microbial pathogens. In FORMATEX microbiology series 4-Microbial pathogens and strategies for combating them: Science, technology and education (pp. 1095-1003). Badajoz: Formatex Research Center.

Metsä-Ketelä, M., Salo, V., Halo, L., Hautala, A., Hakala, J., Mäntsälä, P., \& Ylihonko, K. (1999). An efficient approach for screening minimal PKS genes from Streptomyces. FEMS Microbiology Letters, 180, 1-6.

Mitra, A., Santra, S. C., \& Mukherjee, J. (2008). Distribution of actinomycetes, their antagonistic behaviour and the physico-chemical characteristics of the world's largest tidal mangrove forest. Applied Microbiology and Biotechnology, 80, 685-695.

Mondol, M. A., Shin, H. J., \& Islam, M. T. (2013). Diversity of secondary metabolites from marine Bacillus species: Chemistry and biological activity. Marine Drugs, 11, 2846-2872.

Premanathan, M., Arakaki, R., Izumi, H., Kathiresan, K., Nakano, M., Yamamoto, N., \& Nakashima, H. (2009). Antiviral properties of a mangrove plant, Rhizophora apiculata Blume, against human immunodeficiency virus. Antiviral Research, 44, 113-122.

Qin, S., Li, J., Chen, H. H., Zhao, G. Z., Zhu, W. Y., Jiang, C. L., ... Li, W. J. (2009). Isolation, diversity, and antimicrobial activity of rare actinobacteria from medicinal plants of tropical rain forests in Xishuangbanna, China. Applied and Environmental Microbiology, 75, 6176-6186.

Qin, S., Li, W. J., Dastager, S. G., \& Hozzein, W. N. (2016). Actinobacteria in special and extreme habitats: Diversity, function roles, and environmental adaptations. Frontiers in Microbiology, 7 , 1415.

Rameshkumar, N., \& Nair, S. (2009). Isolation and molecular characterization of genetically diverse antagonistic, diazotrophic red-pigmented vibrios from different mangrove rhizospheres. FEMS Microbiology Ecology, 67, 455-467.

Roy, S., Hens, D., Biswas, D., Biswas, D., \& Kumar, R. (2002). Survey of petroleum-degrading bacteria in coastal waters of Sunderban Biosphere Reserve. World Journal of Microbiology and Biotechnology, 18, 575-581. 
Ryu, C. M., Farag, M. A., Hu, C. H., Reddy, M. S., Wei, H. X., Paré, P. W., \& Kloepper, J. W. (2003). Bacterial volatiles promote growth in Arabidopsis. Proceedings of the National Academy of Sciences of the United States of America, 100, 4927-4932.

Salomon, C. E., Magarvey, N. A., \& Sherman, D. H. (2004). Merging the potential of microbial genetics with biological and chemical diversity: An even brighter future for marine natural product drug discovery. Natural Product Reports, 21, 105-121.

Tamura, K., Stecher, G., Peterson, D., Filipski, A., \& Kumar, S. (2013). MEGA6: molecular evolutionary genetics analysis version 6.0. Molecular Biology and Evolution, 30, 2725-2729.

Thatoi, H., Behera, B. C., Mishra, R. R., \& Dutta, S. K. (2013). Biodiversity and biotechnological potential of microorganisms from mangrove ecosystems: A review. Annals of Microbiology, 63, 1-19.

Thomas, T. R., Kavlekar, D. P., \& LokaBharathi, P. A. (2010). Marine drugs from sponge-microbe association-A review. Marine Drugs, 8, 1417-1468.

Thompson, J. D., Gibson, T. J., Plewniak, F., Jeanmougin, F., \& Higgins, D. G. (1997). The CLUSTAL_X windows interface: Flexible strategies for multiple sequence alignment aided by quality analysis tools. Nucleic Acids Research, 25, 4876-4882.

Wagner-Döbler, I., Beil, W., Lang, S., Meiners, M., \& Laatsch, H. (2002). Integrated approach to explore the potential of marine microorganisms for the production of bioactive metabolites. Advances in Biochemical Engineering/Biotechnology, 74, 207-238.

$\mathrm{Xu}$, J. (2015). Bioactive natural products derived from mangrove-associated microbes. RSC Advances, 5, 841-892. 